\title{
O PNAIC: discussões e análises a partir da formação docente ${ }^{1}$
}

\author{
PNAIC: discussions and analysis from teaching training
}

Maria Betânia de Castro Nunes Santos²

\section{Resumo}

O Pacto Nacional Pela Alfabetização na Idade Certa (PNAIC), política pública implantada em todo o país em 2013, buscou contribuir para o desenvolvimento de ações com o objetivo principal de alfabetizar plenamente todas as crianças até os oito anos de idade. Por meio do presente estudo, buscou-se entender quais as percepções das professoras alfabetizadoras participantes do PNAIC/2014 em Matemática com relação aos temas abordados e as propostas de atuação em sala de aula apresentadas durante este curso de formação. $\mathrm{O}$ referencial teórico fundamentou-se em pesquisa bibliográfica direcionada à formação inicial e continuada do professor alfabetizador, com ênfase na formação de professores alfabetizadores em Matemática. Os dados coletados foram de natureza qualitativa, oriundos de uma entrevista semiestruturada, aplicada a um grupo focal de oito professoras alfabetizadoras, participantes do PNAIC/2014, no município de Lavras - MG. As entrevistas aconteceram individualmente em locais sugeridos pelas professoras, respeitando a disponibilidade das mesmas. Os dados foram analisados dentro das seguintes categorias: Alfabetização/Letramento/Matemática; Formação Continuada; PNAIC/Matemática; PNAIC e aplicabilidade em sala de aula; Sugestões para a melhoria da Educação; e Material didático. A partir da coleta de dados foi possível identificar que o PNAIC, apesar de colaborar, não é suficiente para a formação das profissionais da educação, sendo necessário formação continuada e efetiva em Matemática e que, cursos como o PNAIC não são, por si só, capazes de mudar a Educação de forma imediata, mas que representam um importante passo de uma longa caminhada.

Palavras-chave: PNAIC; Formação de professores; Matemática.

\begin{abstract}
The National Pact for Literacy at the Right Age (PNAIC, acronym in Portuguese), a public policy implemented throughout Brazil in 2013, sought to contribute to the development of actions with the main objective of fully literating all children up to the age of eight. Through this study, we sought to understand what are the perceptions of literacy teachers that took part

\footnotetext{
${ }^{1} \mathrm{O}$ presente trabalho é um recorte da dissertação de mestrado intitulada "Formação continuada de professoras alfabetizadoras em Matemática: a experiência no Pacto Nacional pela Alfabetização na Idade Certa", defendida em 2017 no programa de Mestrado em Educação da Universidade Federal de Lavras - UFLA

${ }^{2}$ Mestre em Educação, Secretaria Municipal de Educação de Lavras, Lavras, Minas Gerais, Brasil. mbetaniacns@gmail.com
} 
of PNAIC/2014 in Mathematics regarding the topics and the proposals presented during this training course. The theoretical framework was based on bibliographic research focused on the initial and continuing training of the literacy teacher, with an emphasis on the training of literacy teachers in Mathematics. The data collected were of a qualitative nature, coming from a semi-structured interview applied to a group of eight literacy teachers that took part of PNAIC/2014, in the municipality of Lavras - MG. The interviews were conducted individually in places suggested by the teachers, respecting their availability. The data were analyzed according to the following categories: Literacy/Literacy in Mathematics; Continuing training; PNAIC/Mathematics; PNAIC and its applicability in the classroom; Suggestions for improving Education; and Teaching material. From the data collection it was possible to identify that PNAIC, despite collaborating, is not enough for the training of education professionals, which requires continuous and effective training in Mathematics and that courses like the PNAIC are not, in themselves, capable of changing Education immediately, but represent an important step in a long journey.

Keywords: PNAIC; Teacher Training; Mathematics.

\section{Introdução}

A preocupação com a Educação no Brasil é necessária e contribui para o desenvolvimento de ações, no sentido de melhorá-la. Ações que possibilitam melhorias para a Educação vêm sendo desenvolvidas, como o Programa de Capacitação de Professores (PROCAP) (GUIMARÃES, 2003), a Plataforma Freire (COELHO NETO; COELHO, 2020) e o Pró-Letramento - Mobilização pela Qualidade da Educação (SÃO JOSÉ, 2012). Dentre essas ações também se encontra o Pacto Nacional Pela Alfabetização na Idade Certa PNAIC, política pública implantada em todo o país, de 2013 a 2017, com o objetivo principal de fazer com que todas as crianças estivessem alfabetizadas, plenamente, até os oito anos de idade. Para alcançar esse objetivo foi necessário unir forças no sentido de tornar realidade, uma ação de tamanha proporção.

Um fator importante para atingir esse objetivo foi investir na formação do professor, tarefa complexa, que precisou contar com o esforço conjunto dos diversos segmentos da sociedade. Por meio da formação continuada de professores dos três primeiros anos do Ensino Fundamental, o PNAIC buscou contribuir para o ensino e aprendizagem, como também para reflexão da prática pedagógica.

Assim sendo, pretendeu-se neste estudo levantar discussões acerca do PNAIC e da formação continuada de professores de Matemática a fim de explicitar quais as percepções de 
professoras alfabetizadoras participantes do PNAIC/2014 em Matemática com relação aos temas abordados e às propostas de atuação em sala de aula. Com a intenção de alcançar tal objetivo, realizou-se pesquisa bibliográfica em documentos e aprofundamento teórico embasados nos estudiosos como Nóvoa (2002), Gadotti (2003), Gatti (2008) e Freire (2003), além de intensa revisão da legislação vigente e aplicação de entrevista semiestruturada com oito professoras alfabetizadoras que participaram da formação do PNAIC em Lavras - MG.

Ressalta-se que de acordo com o limite de laudas, será feito uma breve discussão dos dados coletados, que não afetará a qualidade das informações, bem como das análises feitas no presente trabalho.

\section{Contextualizando o PNAIC}

Para melhor entendimento sobre o contexto do PNAIC faz-se necessário mostrar como ele foi inserido nos programas de políticas públicas para a Educação. Existem alguns documentos que citam essa política apenas como Pacto.

Como política pública entende-se que:

são diretrizes, princípios norteadores de ação do poder público; regras e procedimentos para as relações entre poder público e sociedade, mediações entre atores da sociedade e do Estado. São, neste caso, políticas explicitadas, sistematizadas ou formuladas em documentos (leis, programas, linhas de financiamentos) que orientam ações que, normalmente, envolvem aplicações de recursos públicos (TEIXEIRA, 2012, p. 2).

Ações como o PNAIC, voltadas para a formação continuada de professores, estão embasadas em documentos oficiais, de poder público, sendo, portanto, uma política pública. De acordo com o Ministério da Educação (MEC), o Pacto Nacional pela Alfabetização na Idade Certa foi um compromisso formal, assumido pelo governo federal, Distrito Federal, Estados e Municípios, com o objetivo de assegurar que todas as crianças estivessem alfabetizadas até os oito anos de idade, ao final do $3^{\circ}$ ano do Ensino Fundamental. Essas ações aconteceram em parceria com instituições formadoras e os sistemas públicos de ensino dos estados e municípios.

O PNAIC foi instituído pela Portaria do MEC n 867, de 4 de julho de 2012, na qual 


\section{OO DEVIR EDUCAÇÃO}

ISSN: 2526-849X

foram definidas suas ações e diretrizes gerais e determinado, de acordo com o artigo $1^{\circ}$, a alfabetização em Língua Portuguesa e em Matemática, a realização de avaliações anuais universais, pelo Instituto Nacional de Estudos e Pesquisas Educacionais Anísio Teixeira Inep, para os alunos concluintes do $3^{\circ}$ ano do ensino fundamental e o apoio gerencial dos estados aos municípios que aderiram às ações do Pacto, para sua efetiva implementação.

Em seu Art. $2^{\circ}$, a Portaria n ${ }^{\circ}$ 867, de 4 de julho de 2012, instituiu as ações do PNAIC, em parceria com as instituições formadoras e os sistemas públicos de ensino dos estados, Distrito Federal e municípios, que caracterizaram-se pela integração e estruturação, a partir do eixo Formação Continuada de Professores Alfabetizadores, de ações, materiais e referências curriculares e pedagógicas do MEC, que contribuiriam para a alfabetização e o letramento; pelo compartilhamento da gestão do programa entre a União, Estados, Distrito Federal e Municípios; pela garantia dos direitos de aprendizagem e desenvolvimento, a serem aferidos nas avaliações externas anuais.

O item II do artigo $1^{\circ}$ da Portaria $n^{\circ} 867$, de 4 de julho de 2012, que tratava da realização de avaliações anuais universais, citada também no item III do art. $2^{\circ}$, foi revogado pela Portaria MEC no 369, de 5 de maio de 2016, na qual instituiu-se o Sistema Nacional de Avaliação da Educação Básica - SINAEB, conduzido e planejado pelo Instituto Nacional de Estudos e Pesquisas Educacionais Anísio Teixeira - Inep. Nessa portaria, foram definidas as avaliações externas que seriam realizadas no sistema público de ensino. Uma delas foi a Avaliação Nacional de Alfabetização - ANA. O artigo $8^{\circ}$, item c da Portaria $n^{\circ} 369$, explica que a aplicação da ANA seria bianual, com o objetivo de avaliar a alfabetização e o letramento em Língua Portuguesa e a alfabetização em Matemática dos educandos do $3^{\circ}$ ano do Ensino Fundamental das escolas públicas.

Também chamada de avaliação externa, a Avaliação Nacional de Alfabetização (ANA) foi um instrumento criado pelo MEC com o intuito de acompanhar e avaliar o PNAIC. Sendo censitária, buscou avaliar os conhecimentos do aluno em leitura, escrita e Matemática e com isso, ter um diagnóstico da alfabetização, além de aferir a garantia dos direitos de aprendizagem que são saberes que devem ser consolidados pelo aluno ao final de cada ano do ciclo de alfabetização. O primeiro ano em que a ANA foi aplicada foi em 2013, depois foi aplicada, também, em 2014 e 2016. Faz-se necessário lembrar que a ANA avaliou a alfabetização e não o desempenho dos professores que participaram do PNAIC, mesmo sendo uma política que envolveu a formação e a prática docente. 
O PNAIC possuiu quatro eixos de atuação: 1. Formação continuada presencial para professores alfabetizadores e orientadores de estudo; 2. Elaboração e distribuição de materiais didáticos e pedagógicos por meio do Programa Nacional do Livro Didático (PNLD) e pelo Programa Nacional Biblioteca da Escola (PNBE), além de jogos pedagógicos; 3. Avaliações sistemáticas; 4. Gestão, controle social e mobilização (BRASIL, 2012).

Sendo a proposta do PNAIC a alfabetização até o $3^{\circ}$ ano do Ensino Fundamental em Língua Portuguesa e Matemática, abrangendo escolas públicas, o Eixo 1 trouxe a formação continuada de professores alfabetizadores - ponto principal dessa política. Essa formação foi organizada pensando-se em diversas ações no sentido de oferecer subsídios para os professores alfabetizadores atuarem de forma diferenciada no processo de ensino e aprendizagem (BRASIL, 2012).

De acordo com o documento que institui as diretrizes do PNAIC (BRASIL, 2012), o material disponibilizado pelo Governo Federal foi embasado em documentos e materiais que buscaram garantir a formação do professor e orientá-lo para garantir os direitos de aprendizagem dos alunos.

A formação de professores prevista no PNAIC aconteceu em encontros presenciais nos quais foram realizados estudos teóricos e atividades práticas. Cadernos de formação foram distribuídos aos professores. O PNAIC seguiu o formato de outro curso, ofertado em anos anteriores, e também em nível nacional chamado Pró-Letramento. O Pró-Letramento visava a melhoria da qualidade de ensino e aprendizagem em Linguagem e Matemática no ciclo de alfabetização, ou seja, nos três primeiros anos do ensino fundamental.

Seguindo um planejamento baseado nos cadernos do PNAIC, a formação foi realizada em parceria com universidades federais integrantes da Rede de Formação Continuada e que foram responsáveis por montar uma equipe de Coordenação Geral. Cada estado teve, pelo menos, uma universidade cadastrada - todas públicas, federais ou estaduais. Além disso, fizeram parte dessa equipe os docentes formadores. Nas universidades, aconteceu a capacitação de Orientadores de estudos realizada pelos docentes formadores. Os Orientadores de estudos, por sua vez, repassavam essa capacitação aos professores alfabetizadores de seus municípios em encontros presenciais.

A Portaria n ${ }^{\circ} 1.458$, de 14 de dezembro de 2012 define em seu Art. $2^{\circ}$ que:

a Formação Continuada de Professores Alfabetizadores utilizará material próprio a ser fornecido pelo MEC a todos os orientadores de estudo e 


\section{OO DEVIR EDUCAÇÃO}

ISSN: 2526-849X

professores alfabetizadores cursistas e será ofertada de forma presencial, com duração de:

I - duzentas horas anuais, incluindo atividades extraclasse, para os orientadores de estudo; e

II - cento e vinte horas anuais, incluindo atividades extraclasse, para os professores alfabetizadores (BRASIL, 2012, s/p).

Verificou-se o interesse do MEC em efetivar a política pública para educação com o PNAIC, tendo vários colaboradores já mencionados que contribuíram com as ações necessárias para atingir as metas propostas.

Com relação aos professores alfabetizadores, a formação foi presencial, com carga horária mínima de 120 horas por ano e realizada em cidades-polo espalhadas por todos os estados da federação. A proposta inicial do PNAIC era de dois anos (2013 e 2014), mas se estendeu para os anos de 2015 e 2016. A cada ano, o curso tinha uma temática diferente. Em 2013, a formação foi dedicada à alfabetização (leitura e escrita). Em 2014, o foco foi a Matemática, onde foram trabalhados os cadernos específicos da disciplina e, também, aprofundamento dos temas tratados em 2013. A carga horária foi de 160 horas, sendo 120 horas destinadas à Matemática e 40 horas à Língua Portuguesa objetivando o reforço do que havia sido trabalhado em 2013 (BRASIL, 2016).

Em cada Estado, havia uma ou mais estruturas de Coordenação institucional/geral responsáveis pela implementação e administração do PNAIC. O Coordenador geral e os Coordenadores municipais eram responsáveis, entre outras atribuições, por cadastrar todos os participantes no Sistema Integrado Monitoramento Execução e Controle (SIMEC), organizar o calendário acadêmico e garantir a infraestrutura nas cidades-polo. Também era responsabilidade do Coordenador local zelar pela aplicação da Avaliação Nacional de Alfabetização (ANA).

O SIMEC, vinculado ao Programa de Ações Articuladas (PAR), monitorou o registro e as informações sobre o PNAIC, em que todos os envolvidos podiam acessar informações sobre o curso. No SIMEC, os professores cursistas, os Orientadores de estudo e o Coordenador de local, podiam acessar as informações e realizar avaliações sobre o desempenho dos envolvidos no processo formativo do PNAIC.

Por meio da Portaria No. 1.458, de 14 de dezembro de 2012 (BRASIL, 2012), os professores alfabetizadores e, também, os demais envolvidos na formação recebiam um incentivo financeiro mensal, enquanto durasse a formação.

Com relação ao Eixo 2, o MEC disponibilizava os materiais didáticos que eram 


\section{Q DEVIR EDUCAÇÃO \\ ISSN: 2526-849X}

entregues aos municípios conforme o número de turmas de alfabetização. Já no Eixo 3, o foco concentrou-se na avaliação dos resultados de todo processo de alfabetização, ao final do terceiro ano do ciclo de alfabetização, com a aplicação da ANA. No Eixo 4, a meta era verificar como se conduzia a gestão, controle social e mobilização dos agentes envolvidos nesse processo.

De acordo com o Instituto Brasileiro de Geografia e Estatística (IBGE) e o Ministério da Educação (MEC), o PNAIC atingiu em 2013, em seu primeiro ciclo, 5420 municípios. Em 2014, segundo ciclo, 5497 municípios e em 2015, 5501 municípios no terceiro ciclo. Implantado em todo o território nacional, os desafios se multiplicavam e se dividiam pelo país, com quarenta universidades atuando como instituições formadoras dos Orientadores de estudos (CARDOSO, 2017).

A adesão e envolvimento das esferas federal, estadual e municipal, para a implantação e desenvolvimento desse programa, transfromou-o em um dos mais importantes empreendimentos para promover a conscientização de que a alfabetização merece um olhar especial no processo de melhoria da educação em todo o país. Para isso, é importante considerar que o direito à Educação, embasado por lei, precisa e deve ser respeitado. Só assim pode-se pensar num país mais digno para se viver, onde todos os cidadãos terão a mesma oportunidade no mercado de trabalho e na sociedade.

\section{A formação de professores e o PNAIC}

Entendida como um processo constante de aprendizagem e aperfeiçoamento de saberes necessários à atuação profissional, a formação continuada de professores tem por objetivo melhorar a prática docente, o conhecimento e principalmente a reflexão sobre a sua docência. De acordo com Freire (2003, p. 28):

A responsabilidade ética, política e profissional do ensinante lhe colocam o dever de se preparar, de se capacitar, de se formar antes mesmo de iniciar sua atividade docente. Esta atividade exige que sua preparação, sua capacitação, sua formação se tornem processos permanentes. Sua experiência docente, se bem percebida e bem vivida, vai deixando claro que ela requer formação permanente do ensinante. Formação que se funda na análise crítica de sua prática. 
A adaptação às mudanças, tanto no meio educacional quanto na sociedade, colaboram para que essa formação seja efetivada e valorizada. Ações que podem complementar a formação continuada do professor são citadas por Gatti (2008, p. 57) como:

Horas de trabalho coletivo na escola, reuniões pedagógicas, trocas cotidianas com os pares, participação na gestão escolar, congressos, seminários, cursos de diversas naturezas e formatos, oferecidos pelas Secretarias de Educação ou outras instituições para pessoal em exercício nos sistemas de ensino, relações profissionais virtuais, processos diversos à distância (vídeo ou teleconferências, cursos via internet, etc.), grupos de sensibilização profissional, enfim, tudo que possa oferecer ocasião de informação, reflexão, discussão e trocas que favoreçam o aprimoramento profissional, em qualquer de seus ângulos, em qualquer situação.

Nas últimas décadas, o Brasil tem passado por reformas estruturais e curriculares na educação, como o Ensino Fundamental de nove anos e a obrigatoriedade da pré-escola. Percebem-se movimentos no sentido de que ações governamentais colaborem para uma melhoria na educação e, como consequência, na vida escolar dos alunos. Uma das formas de se melhorar a educação é o investimento em programas de formação, "no sentido de estimular a gênese de uma cultura da formação contínua de professores" (NÓVOA, 2002, p. 63).

Contudo, cabe aqui ressaltar que há um caminho longo a ser percorrido, tanto pela necessidade dessa formação e a busca por novos conhecimentos, como também pela transformação do professor e sua prática. Sendo assim, "a formação contínua deve estar articulada com o desempenho profissional dos professores, tornando as escolas como lugares de referência" (NÓVOA, 2002, p. 63). Além de reflexiva e permanente, "a formação do profissional da educação está diretamente relacionada com o enfoque, a perspectiva, a concepção mesma que se tem da sua formação e de suas funções atuais" (GADOTTI, 2003, p. 38) e deve ser permanente. O professor deve buscar sempre a aprendizagem e o aperfeiçoamento desta, por meio da reflexão sobre sua prática.

A partir disso, levando em consideração a formação continuada em Matemática, percebe-se que existe uma lacuna na formação inicial da "professora polivalente", tanto na formação em nível médio quanto na formação em nível superior. Segundo Nacarato, Mengali e Passos (2009, p. 17), essa lacuna se deu por não haver "educadores matemáticos que trabalhassem com as disciplinas voltadas à metodologia de ensino de matemática - muitos eram pedagogos, sem formação específica" - o que colaborou para "uma formação centrada 


\section{OO DEVIR EDUCAÇÃO}

ISSN: 2526-849X

em processos metodológicos, desconsiderando os fundamentos da matemática. Isso implicava em uma formação com muitas lacunas conceituais nessa área do conhecimento" (NACARATO; MENGALI; PASSOS, 2009, p. 18).

Pensando nesse professor que atua nos anos iniciais e que é responsável pela base do ensino dessa disciplina, tão importante para a vida dos alunos, fica evidente a dificuldade de ensinar conceitos que nem ele mesmo domina bem ou que desconheça, evidenciando a estreita ligação entre o aprender e o ensinar. Só se tem segurança em ensinar aquilo que se aprendeu. Pensando nesses professores que possuem lacunas em sua formação e, também, naqueles que podem aprender algo mais, principalmente no sentido de ampliar os conhecimentos para atender às demandas que a profissão exige, alguns cursos de formação continuada foram criados como o PROCAP, PLATAFORMA FREIRE, PRÓLETRAMENTO e o PNAIC, sendo este último relacionado a este trabalho.

\section{Contextualizando o local e as participantes}

O contexto do presente estudo foi a formação continuada de professores em Matemática por meio do Pacto Nacional Pela Alfabetização na Idade Certa - PNAIC, no ano de 2014, com um grupo de professoras alfabetizadoras que participaram do referido programa, na cidade de Lavras, sul de Minas Gerais.

Para participar da pesquisa, escolheu-se intencionalmente um grupo de oito professoras dos anos iniciais do Ensino Fundamental. A aplicação das entrevistas aconteceu durante o mês de dezembro de 2016. E a partir delas foi possível verificar que todas as oito participantes são do gênero feminino. Isto justifica, na maioria das vezes, a ausência do docente do gênero masculino, pois quando se pensa no perfil do professor para os anos iniciais, existe uma cultura que prega que a docente do gênero feminino tem mais paciência, dá mais atenção à criança e também mais carinho, enquanto que o docente do gênero masculino é visto como sujeito paternal e autoritário. Estudos discutindo questões de gênero e o número reduzido de homens na docência são encontrados em Cardoso (2007), Fonseca (2010) e Silva (2014), dentre outros.

A faixa etária das professoras participantes dessa pesquisa variou de 38 a 61 anos. Das 
oito professoras entrevistadas, seis cursaram o Magistério. Foi possível identificar que, cinco dessas professoras fizeram o Magistério na década de 1980 e apenas uma fez na década de 1990 (professora G). As professoras B e C não cursaram o Magistério. Estas duas professoras fizeram a graduação em Pedagogia, o que fez com que elas se tornassem aptas também a lecionar nos anos iniciais do Ensino Fundamental, amparadas por lei.

Ainda com relação à formação das professoras, todas possuíam Ensino Superior, sendo que quatro fizeram o curso de Pedagogia (professoras A, B, C, D) e duas fizeram o curso Normal Superior (professoras G e H). A professora E cursou Filosofia e a professora F cursou Biologia. A professora B tinha uma segunda formação em Biologia, sendo esta formação anterior à de Pedagogia. De acordo com os dados do INEP (BRASIL, 2017), do total de docentes que atuavam nas turmas de anos iniciais, 74,8\% têm nível superior completo. Percebe-se que o grupo de professoras que participou da pesquisa supera, nesse sentido, a média do país.

Das oito, seis professoras possuem curso de Pós-Graduação, sendo duas em Psicopedagogia (professoras C e F), uma em Educação (professora A), uma em Teorias e Práticas na Educação (professora B), uma em Gestão Escolar (professora D) e uma em Práticas de Letramento e Alfabetização (professora H). A professora E começou um curso de Pós-Graduação em Psicopedagogia, em 2006, mas não concluiu. A professora G não possui Pós-Graduação. A professora A fez ainda uma segunda Pós-Graduação em Orientação Educacional, Supervisão Escolar e Gestão Educacional. Percebe-se que a maioria das professoras possuem formação em curso de Pós-Graduação. Isso indica que há consciência da necessidade de novas formações e que esta busca acontece no grupo pesquisado. Além da consciência da importância da formação, existe o fator salarial que atua como motivador na busca por qualificação, como citam Biazi (2010), Dourado (2015) e Jacomini e Camargo (2011), entre outros. Outro ponto importante é a busca pela formação que não seja voltada necessariamente à área de atuação da professora, mas que colabora no aumento do seu salário, como cita Gatti (2008, p. 64-65):

Tudo que é relativo à formação profissional ou definido como "para áreas profissionais" é ignorado pelos educadores e gestores em educação, como se a educação não fosse propriamente uma "área profissional", ou não comportasse subáreas especializadas. Por essa razão, temos, no campo da educação, formações em especialização que não habilitam para funções especializadas, ficando apenas a graduação como delimitadora para esse exercício, sem maiores aprofundamentos. Os cursos de especialização em 


\section{Q DEVIR EDUCAÇÃO \\ ISSN: 2526-849X}

áreas específicas de trabalho são objeto de uma regulamentação exigente, desconhecida de modo geral pelos setores profissionais da educação. Assim, as normatizações exaradas para essa modalidade são deixadas de lado pelos gestores educacionais. Os cursos de especialização em educação não habilitam com certificação profissional, como ocorre em outras áreas do trabalho e, embora contribuam para aprofundamentos formativos, do ponto de vista do exercício profissional, apenas entram como "pontuação" em carreiras ligadas ao ensino. É esse tipo de curso, sem exigências especiais até aqui, que prolifera como proposta de educação continuada.

Diante disso, no grupo das professoras participantes dessa pesquisa, percebeu-se que a formação em nível de pós-graduação não trata especificamente do processo de alfabetização, sendo que apenas uma das professoras cursou pós-graduação em Alfabetização e Letramento.

\section{Análise dos dados}

A coleta dos dados analisados e discutidos neste estudo se deu a partir da participação de oito professoras ${ }^{3}$ alfabetizadoras no curso de formação do PNAIC/2014, que ocorreu no município de Lavras - MG. As professoras se dispuseram a participar da entrevista semiestruturada, em que foram abordados alguns assuntos como o PNAIC, práticas docentes, formação continuada, entre outras questões. As respostas foram analisadas considerando-se, principalmente, as seguintes categorias: Formação Continuada, PNAIC/Matemática, PNAIC e aplicabilidade em sala de aula, Sugestões para a melhoria da Educação, e Material didático.

Ao falarem sobre formação continuada, abriu-se um leque, pois ao relatarem sobre o tema, as professoras voltaram-se principalmente à formação em questão, o PNAIC. Por isso, foram analisados, aqui, alguns recortes mais relevantes das respostas das professoras. Seis professoras responderam que a formação continuada é importante, utilizando expressões como "não se acomodar", "não ficar na rotina", "buscar conhecimento", e "aperfeiçoar". A professora A relacionou essa pergunta apenas ao PNAIC e a professora C relatou que já questionou muito a formação continuada, pois "ela é muito repetitiva e a gente estava vendo sempre as mesmas coisas" e, em seguida, passou a elogiar o PNAIC por ser diferente das outras experiências que já vivenciou.

Relacionando a categoria com a formação em questão, constatou-se que a participação

\footnotetext{
${ }^{3}$ A fim de manter o anonimato das professoras, substituiu os nomes por letras do alfabeto.
} 
dessas professoras no PNAIC deu-se por motivos diferentes. A professora A relata que "foi por causa do governo. O que o governo pretende conosco sendo alfabetizadoras?" e também para "fazer uma reciclagem". As professoras B e E foram convidadas a participar por estarem na alfabetização. Já as professoras C e H por gostarem de estudar. A professora D não participou, no ano de 2013, da Formação em Língua Portuguesa, por estar na Educação Infantil, porém teve acesso ao material. No ano de 2014, ela foi para a alfabetização e fez a formação. A professora F relatou a "necessidade de ter assim um apoio", pois na sua fala percebeu-se a preocupação com as mudanças que vêm ocorrendo na sala de aula com relação ao perfil do aluno e as demandas para acompanhar essas mudanças. Um discurso interessante foi o da professora $G$ que se interessou pelo curso por achar que era uma coisa boa, mas também porque "ia ter bolsa, que é um incentivo e por causa dessa lei em que a criança tem que estar alfabetizada até o $3^{\circ}$ ano". Mais uma vez, observou-se o fator financeiro como um motivador da participação do professor nessa formação.

Ao serem questionadas sobre o impacto do PNAIC na formação, as professoras foram unânimes em afirmar que o PNAIC acrescentou conhecimentos importantes para suas práticas pedagógicas. Uma resposta que chamou a atenção foi da professora $\mathrm{C}$ quando falou que "todo ano a gente está com alunos diferentes, turmas diferentes, problemas diferentes. A aprendizagem não é igual pra todos os alunos" justificando a importância da formação. A professora E relatou que "eu acho que o curso tem que mudar a prática; se não mudar, não valeu, não alcançou o objetivo". Portanto, as professoras viram o PNAIC como sendo útil e, aparentemente, compreenderam a importância do programa. Sendo assim, a professora E afirmou:

Foi muito bom [...] Queria que o PNAIC continuasse com seriedade. A gente tem que pensar nos meninos. Eles são o futuro. Eles que vão estar amanhã na liderança do país. Que dê continuidade. Deveria estender para o $4^{\circ}$ e $5^{\circ}$ anos. Que tivesse sequência.

As oito professoras ressaltaram que gostaram dos encontros, porém três delas registraram como parte negativa a duração e os dias dos encontros, pois os mesmos aconteciam geralmente aos sábados (com duração de oito horas e foram considerados longos e cansativos por essas professoras), assim como nas quartas-feiras à noite, com duração de quatro horas. O reduzido tempo disponível para a realização dos encontros (maio a dezembro) fez com que os mesmos fossem condensados, justificando as ponderações das professoras. 
As professoras mencionaram alguns momentos dos encontros, citando atividades, jogos e a forma como certos conceitos foram trabalhados. Falaram ainda das dificuldades de alguns tópicos da Matemática, mas todas gostaram da forma como foram trabalhados e há relatos muito importantes como: "muda o jeito da gente pensar, de trabalhar dentro de sala" (professora B); "tem uns que eu preciso voltar um pouquinho" disse a professora D, referindo-se à Geometria; a professora E ressaltou que "pode trabalhar de maneiras diferentes, ou seja, maneiras mais lúdicas, mais divertidas. Hoje quando eu pego o livro didático, eu tenho mais facilidade"; já a professora $\mathrm{H}$ relatou que "foi muita coisa que foi passada [...] o conteúdo foi muito grande. Muita matéria. Foi muita coisa".

Nota-se que, ao avaliar a forma como os temas foram abordados, as professoras tenderam a fazer uma autoavaliação e uma reflexão da sua prática, o que é muito válido, pois ao refletir sobre seus métodos, o docente comprometido com sua prática tende a atuar de maneira mais adequada e eficiente. No caso específico da alfabetização, em que novas propostas estão surgindo, tal processo de avaliação formativa é ainda mais importante. Nunes (2001,p. 30) ressalta ainda que deve-se:

[...] considerar o professor em sua própria formação, num processo de autoformação, de reelaboração dos saberes iniciais em confronto com sua prática vivenciada. Assim, seus saberes vão-se construindo a partir de uma reflexão na e sobre a prática. Essa tendência reflexiva vem-se apresentando como um novo paradigma na formação de professores, sedimentando uma política de desenvolvimento pessoal e profissional dos professores e das instituições escolares.

A importância da formação continuada para efetivar a reflexão sobre a prática é demonstrada quando se percebe a troca de experiências, a interação do grupo e o estreitamento das relações. Perceber que seus pares também necessitam da reelaboração de saberes que já estavam "enraizados” e que precisam ser passados aos alunos de forma diferente e que colaborem para a aprendizagem, só tende a contribuir para a melhoria do processo educacional.

Com relação aos destaques, muita ênfase foi dada aos materiais didáticos apresentados e suas potencialidades, em especial a "caixa matemática", o "livrinho da girafa", o método de "medição com o barbante", a utilização de "suco e salada de frutas para trabalhar quantidade e capacidade", as "atividades com palitos, jogos, fio de contas". Sobre esses materiais, as professoras fizeram relatos mais ricos e extensos quando analisaram os cadernos que foram 
estudados durante a formação.

No que diz respeito ao que deveria ter sido trabalhado mais ou de forma diferente: para a professora B, a multiplicação; já para as professoras D e E foi a Geometria; a professora E também ressaltou a dificuldade no tópico Grandezas e Medidas; a professora $\mathrm{H}$ ressaltou a dificuldade em ensinar o Sistema de Numeração Decimal; a professora B acha que a parte da multiplicação e divisão deveriam ser mais trabalhadas para que ela pudesse ensinar seus alunos com mais segurança e ela ressaltou que "se a criança não trabalhou bem (a multiplicação e a divisão), a criança vai ter dificuldade na fração". Percebeu-se que a cultura da formação da professora "polivalente" (CRUZ; BATISTA NETO, 2012; LIMA, 2007) - em que uma professora é responsável por ministrar conteúdos de diversas áreas como Língua Portuguesa, Matemática, Ciências da natureza e da sociedade e demais conhecimentos fundamentais para a formação das crianças - leva muitas vezes a docente ao conhecimento superficial de cada uma das áreas e a dificuldade e, até mesmo, insegurança em ministrar conteúdos de cada uma delas. Além disso, Cavalcante e Vituriano (2016, p. 6):

\footnotetext{
A tarefa de ensinar não é simples porque o/a professor/a, além de conhecer os conteúdos didáticos, precisa entender como os/as alunos/as desenvolvem suas habilidades no dia a dia da sala de aula. O/a professor/a deve conhecer a realidade de seus alunos para que seu trabalho gere uma aprendizagem significativa, pois está trabalhando com múltiplas linguagens e múltiplas culturas.
}

Constatou-se, também, que as dificuldades apresentadas por essas professoras possuem raízes na formação inicial, que na maioria das vezes "não dá conta dos desafios com que os professores se deparam diariamente no cotidiano escolar" (CAVALCANTE; VITURIANO, 2016, p. 5). Esses autores dizem que, no caso da Matemática, fica mais evidente, quando se parte do princípio de que o professor já tem os conhecimentos básicos dessa disciplina e que não terá dificuldade de ensiná-los.

\section{Considerações Finais}

Este trabalho teve como propósito investigar quais as percepções das professoras alfabetizadoras participantes do PNAIC/2014 em Matemática com relação aos temas 
abordados e as propostas de atuação em sala de aula, apresentadas durante este curso de formação. Para obter sucesso optou-se por ouvir um grupo de oito professoras da cidade de Lavras, sul de Minas Gerais, que participaram do PNAIC/2014. Para isso, foi necessário um embasamento teórico, que consistiu principalmente no estudo de obras voltadas para a formação continuada de professores, com destaque para os trabalhos de Nóvoa, Gadotti, Gatti e Freire, além de intensa revisão da legislação vigente.

Diante disso, observou-se, primeiramente, que uma política pública, criada com a intenção de colaborar para a melhoria da qualidade no processo de alfabetização foi aceita e aprovada pelo grupo de professoras alfabetizadoras que participaram da trabalho. Percebeu-se também que cursos como o PNAIC não são, por si só, capazes de mudar a Educação de forma imediata, mas que representam um importante passo de uma longa caminhada. Portanto, ficou evidente, na fala das professoras, a importância do PNAIC no processo de formação continuada, assim como a continuidade desse programa para a melhoria da/na prática pedagógica. Um aspecto que mereceu destaque foi a troca de experiências que colaborou para a reflexão sobre a prática docente. Notou-se a importância de se dar vez e voz ao professor, mesmo que seja nesses momentos de formação.

Sendo assim, ao analisar a formação PNAIC/Matemática 2014, finalmente considerouse que é necessário ampliar, aprofundar e conscientizar as professoras sobre a importância de estudos teóricos aliados à prática, principalmente no que tange à alfabetização matemática. Ações como o PNAIC devem ser efetivas e ter continuidade para que se possa garantir que as crianças estejam plenamente alfabetizadas.

Assim, algumas propostas para futuros encontros de formação continuada do PNAIC, como também outros cursos de formação, devem valorizar e reconhecer o professor que, mesmo com toda a dificuldade de formação, está à frente de uma sala de aula e que precisa desse apoio para vencer as barreiras enfrentadas no dia a dia do seu trabalho e também na sua formação. Oferecer oportunidades para esse professor polivalente, no sentido de sanar as dificuldades apresentadas por ele com relação à Matemática, é outro fator que merece destaque. A formação continuada serve também para fortalecer as relações interpessoais e profissionais dessas professoras, por isso a importância dos encontros de formação.

Por fim, o tema formação continuada do professor alfabetizador deve ser sempre objeto de estudos acadêmicos ampliados constantemente. Futuros trabalhos com essa temática devem ser realizados, pois a busca pela qualidade da educação, tão evidenciada atualmente, 
onde se preza pela formação do professor e pela motivação do mesmo pelo seu trabalho, perpassa por efetivar o valor da educação dita básica, que é uma determinação legal e direito de todos.

\section{Referências}

BIAZI, M. H. Formação continuada: a importância do professor se qualificar.

Revista Eventos Pedagógicos, Sinop, v. 1, n. 1, p. 108-109, ago./dez. 2010.

BRASIL. Ministério da Educação. Portaria n⿳ 867, de 4 de julho de 2012. Institui o Pacto pela Educação na Idade Certa e as ações do Pacto e define suas diretrizes gerais. Brasília, DF, 2012a. Disponível em: http://pacto.mec.gov.br/images/pdf/2016/Portarias/PORTARIA_N_867_DE_4_DE_JULH O_DE_2012.pdf. Acesso em: 20 de mai. 2020.

BRASIL. Ministério da Educação. Portaria no 1.458, de 14 de dezembro de 2012. Define categorias e parâmetros para a concessão de bolsas de estudo e pesquisa no âmbito do Pacto Nacional pela Alfabetização na Idade Certa. Brasília, DF, 2012b. Disponível em: http://www.pacto.gov.br. Acesso em: 22 de mai. de 2020.

BRASIL. Ministério da Educação. Portaria no 369, de 05 de maio de 2016. Institui o Sistema Nacional de Avaliação da Educação Básica - SINAEB. Diário Oficial da União, Brasília, DF, 6 de maio 2016a. Seção 1, p. 26.

BRASIL. Ministério da Educação. Censo escolar da educação básica 2016: notas estatísticas. Brasília, DF, 2017. (Notas Estatísticas - Censo Escolar 2016). Disponível em:

http://www.inep.gov.br/educacao_basica/censo_escolar/notas_estatisticas/2017/_censo_ esco lar_da_educacao_basica_2016.pdf. Acesso em: 19 de mai. de 2020.

CARDOSO, M. Pnaic chega à reta final acenando resultados e desafios. Disponível em: http://www.plataformadoletramento.org.br/em-revista-reportagem-detalhe/972/pnaicchega- a-reta-final-acenando-resultados-e-desafios.html. Acesso em: 22 de mai. de 2020.

CAVALCANTE, D. P. de S.; VITURIANO, N. F. da S. Os desafios e perspectivas na formação do professor da educação infantil e ensino fundamental: semelhanças e diferenças entre as duas etapas da educação básica. 2016. Disponível em:

http://www.editorarealize.com.br/revistas/fiped/trabalhos/Trabalho_Comunicacao_oral_idi n scrito_1340_1a278309e9af03c3cd1f0e84225d7981.pdf. Acesso em: 20 de mai. 2020.

COELHO NETO, A.; COELHO, P. Reflexões sobre a experiência formativa na 
plataforma Freire em cursos de licenciatura em geografia. Geografia Ensino \& Pesquisa, v. 24, e3, fev. 2020.

CRUZ, S. P. da S.; BATISTA NETO, J. A polivalência no contexto da docência nos anos iniciais da escolarização básica: refletindo sobre experiências de pesquisas. Revista Brasileira de Educação, Rio de Janeiro, v. 17, n. 50, p. 385-499, maio/ago. 2012.

DOURADO, L. F. Diretrizes Curriculares Nacionais para a Formação Inicial e Continuada dos profissionais do Magistério da Educação Básica: concepções e desafios. Educação e Sociedade, Campinas, v. 36, n. 131, p. 299-324, abr./jun. 2015.

FONSECA, T. S. M. O professor homem nos anos iniciais do ensino fundamental: formação e feminização: questões de gênero? 2010. Disponível em:

http://wp.ufpel.edu.br/antoniomauricio/files/2015/02/cadernos-421x318.jpg. Acesso em: 20 mai. De 2020.

FREIRE. P. Professora sim, tia não: cartas a quem ousa ensinar. 14. ed. São Paulo: Olho d'Água, 2003.

GADOTTI, M. Boniteza de um sonho: ensinar e aprender com sentido. Novo Hamburgo: Feevale, 2003. Disponível em: http://www.feevale.br/Comum/midias/93aeebed-9c8b4b56- 8341-22ac5cd3b501/Boniteza\%20de\%20um\%20Sonho.pdf. Acesso em: 20 de mai. de 2020.

GATTI, B. A. Análise das políticas públicas para formação continuada no Brasil, na última década. Revista Brasileira de Educação, Rio de Janeiro, v. 13, n. 37, p. 57-70, jan./abr.

2008.

GUIMARÃES, L. M. Longe da escola, na escola: os significados do PROCAP na construção dos saberes e na prática dos professores. 2003. Disponível em: https://repositorio.ufu.br/bitstream/123456789/13714/1/Lidonia.pdf

JACOMINI, M. A.; CAMARGO, R. B. de. Carreira e salário do pessoal docente da educação básica: algumas demarcações. Educação em Foco, Juiz de Fora, ano 14, n. 17, p. 129-167, jul. 2011.

NACARATO, A. M.; MENGALI, B. L. S.; PASSOS, C. L. B. A matemática nos anos iniciais do ensino fundamental: tecendo fios do ensinar e do aprender. Belo Horizonte: Autêntica, 2009.

NÓVOA, A. Concepções e práticas de formação contínua de professores. In: _. Formação contínua de professores: realidade e perspectivas. Lisboa: Universidade de Aveiro, 2002. p. 49-66.

SÃO JOSÉ, L. Os efeitos do pró-letramento na formação das professoras alfabetizadoras do município de Conselheiro Lafaiete. 2012. Disponível em: 


\section{OO DEVIR EDUCAÇÃO}

ISSN: 2526-849X

https://repositorio.ufmg.br/bitstream/1843/BUOS-

8ZKR77/1/dissertacao_lucimara_22_setembro.pdf

TEIXEIRA, E. C. O. Papel das políticas públicas no desenvolvimento local e na transformação da realidade. Salvador: Associação dos Advogados de Trabalhadores Rurais Bahia, 2012. Disponível em:

http://www.dhnet.org.br/dados/cursos/aatr2/a_pdf/03_aatr_pp_papel.pdf. Acesso em: 23 mai. 2020. 